\title{
Moving Filter Filtration
}

National Cancer Institute

\section{Source}

National Cancer Institute. Moving Filter Filtration. NCI Thesaurus. Code C113001.

The use of a rotary drum, belt, or other moving filter to purify a slurry. 